\title{
Proposta de melhoria de aterro de resíduos sólidos urbanos para um pequeno município
}

\section{Proposal for improvement of urban solid waste landfill for a small municipality}

\author{
André Franco Guerra ${ }^{[a]}$, Carlos Magno de Sousa Vidal ${ }^{[b]}$, Jeanette Beber de Souza ${ }^{[c]}$ \\ [a] Engenheiro ambiental pela Universidade Estadual do Centro-Oeste (UNICENTRO), Irati, PR - Brasil, e-mail: \\ guerra.ambiental@hotmail.com \\ [b] Biólogo, professor Doutor do Departamento de Engenharia Ambiental da Universidade Estadual do Centro-Oeste \\ (UNICENTRO), Irati, PR - Brasil, e-mail: cacavidal@yahoo.com.br \\ [c] Engenheira Civil, professora Doutora do Departamento de Engenharia Ambiental da Universidade Estadual do Centro-Oeste \\ (UNICENTRO), Irati, PR - Brasil, e-mail: jeanettebeber@yahoo.com.br
}

\section{Resumo}

O objetivo do presente trabalho foi realizar um diagnóstico do aterro de disposição de resíduos do município de Taquarituba, SP, empregando metodologia que avalia o Índice de Qualidade de Aterro de Resíduos (IQR), levando-se em consideração as características do local, a infraestrutura implantada e as condições operacionais. $\mathrm{O}$ resultado obtido para IQR foi de 4,46, o que indicou condições inadequadas para o aterro. Baseado no resultado da avaliação e considerando os escassos recursos financeiros do município, foram propostas soluções para enquadrar a área como aterro sanitário. Como método de operação, foram propostas grandes trincheiras, com utilização do próprio solo local para recobrimento diário dos resíduos, e impermeabilização das trincheiras. Além disso, foram projetados sistemas de drenagem e recirculação de lixiviados, drenagem de águas pluviais, drenagem de gases através de dutos construídos com pneus inservíveis, e estruturas de controle como cercas e guarita. As medidas propostas apresentaram simplicidade construtiva e operacional com o objetivo de atender à realidade financeira da prefeitura municipal e concomitantemente proporcionar melhoria da qualidade ambiental. Após a proposta de melhoria, o novo IQR do aterro foi de 9,60, o que enquadrou a área como aterro sanitário e possibilitou aumentar sua vida útil de 4 para 8,8 anos.

Palavras-chave: Resíduos sólidos urbanos. Gerenciamento de resíduos sólidos. Aterro sanitário. 


\begin{abstract}
The objective of this work was to accomplish a diagnosis in the landfill about solid waste disposal in Taquarituba, SP, applying a methodology to evaluate the Solids Waste Quality Indicator (IQR), taking into account the local characteristics, the infrastructure and the operational conditions. The result obtained for IQR was 4.46, what showed non-proper conditions for the landfill. Based on the evaluation result and considering the low financial resources of the city, solutions were proposed to frame the area as sanitary landfill. As an operational method, large trenches were proposed, using the soil itself for covering solid waste daily and waterproofing the trenches. Besides, drainage systems and lixiviated recirculation were projected, drainage of pluvial water, drainage of gases through ducts built with useless tires and control structures as fences and watch tower. The proposed steps presented constructive and operational simplicity with the objective of assisting the financial reality of the city hall and concomitantly provide improvement of environmental quality. After the improvement proposal the new IQR was of 9.60, which framed the area as sanitary landfill and it facilitated the increase of its useful life from 4 to 8.8 years.
\end{abstract}

Keywords: Urban solid waste. Solid waste management. Sanitary landfill.

\title{
Introdução
}

Dentre as alternativas mais utilizadas para a disposição dos resíduos sólidos urbanos (RSU) estão à disposição, a céu aberto, o aterro controlado e o sanitário, sendo este último considerado o mais adequado.

Na Norma Técnica Brasileira NBR 8849 (ABNT, 1985) estão fixadas as condições mínimas exigidas para a apresentação de projetos de aterros controlados de resíduos sólidos urbanos. Segundo essa norma, a execução de um aterro controlado adota algumas precauções tecnológicas, como sistema de drenagem de águas pluviais, recobrimento dos resíduos com argila, dispositivo de isolamento da área e outras medidas que aumentam a segurança do local, mas que não são totalmente ideais.

Na Norma Técnica Brasileira NBR 8419 (ABNT, 1992, p. 1) estão fixadas as condições mínimas exigidas para a apresentação de projetos de aterros sanitários de resíduos sólidos urbanos. Segundo essa norma,

os resíduos são dispostos no solo sem causar danos à saúde pública, bem como à segurança da população, minimizando os impactos ambientais. O aterro sanitário utiliza princípios de engenharia para confinar os resíduos sólidos à menor área possível e reduzi-los ao menor volume permissível, cobrindo-os com uma camada de terra na conclusão de cada jornada de trabalho, ou a intervalos menores, se necessário.

Essa técnica apresenta dispositivos como: sistema de drenagem periférica e superficial de águas pluviais, sistema de drenagem e tratamento de percolado, e de drenagem de gases produzidos no processo de degradação da matéria orgânica, entre outros.

De acordo com o Instituto de Pesquisas Tecnológicas (IPT, 2000), a contínua avaliação das formas de tratamento e disposição final dos resíduos de um município é uma atividade fundamental e de competência dos órgãos públicos municipais, que, se não for realizada, compromete em maior ou menor grau os compartimentos ambientais, muitas vezes tornando em verdadeiros lixões áreas originalmente projetadas para servir como aterros sanitários. Para a definição dos procedimentos mais adequados a serem tomados deve-se primeiramente realizar um diagnóstico da situação atual do município, pois é a partir dessa avaliação que se tornam conhecidas as condições favoráveis e desfavoráveis existentes, o que permite priorizar as medidas eventualmente necessárias.

Ainda de acordo com o Instituto de Pesquisas Tecnológicas/Compromisso Empresarial para Reciclagem (IPT/CEMPRE, 2000, p. 257), a adequação de aterro existente "trata-se de um processo que visa o aperfeiçoamento progressivo de área de disposição de lixo, habilitando-a à condição mais próxima possível das de um aterro sanitário, ao longo de toda sua vida útil”.

Rev. Acad., Ciênc. Agrár. Ambient., Curitiba, v. 8, n. 2, p. 191-203, abr./jun. 2010 
O aterro de disposição de resíduos do município de Taquarituba, localizado a $320 \mathrm{~km}$ de São Paulo, era classificado como controlado e possuía Licença de Operação (LO); no entanto, sua incorreta operação acarretou sérias pressões da Companhia de Tecnologia e Saneamento Ambiental do Estado de São Paulo (Cetesb), que exigiu dos gestores públicos do município a adequação em relação à forma e ao local de disposição final dos resíduos sólidos até então praticada. Assim, o presente trabalho teve como objetivo realizar o diagnóstico ambiental do referido aterro e propor medidas de adequação deste.

\section{Materiais e métodos}

\section{Caracterização da área de estudo}

A disposição dos RSU de Taquarituba é realizada em uma propriedade da prefeitura, que conta com área de 4,43 ha, situada no bairro Queimadão, distante cerca de $9 \mathrm{~km}$ do centro da cidade. A área está localizada na zona rural e faz divisa com pequenas chácaras e sítios. A região não possui legislação municipal específica de uso do solo. A bacia de drenagem da localidade não é a mesma que a do manancial de abastecimento de água da cidade. O acesso ao local é feito pela estrada vicinal Orvalino Marcelino da Costa, que liga Taquarituba a wá, com asfalto de boa trafegabilidade.

\section{Avaliação e diagnóstico do aterro de Taquarituba}

Foram realizadas visitas técnicas rotineiras à área de estudo no ano de 2006 para averiguação da situação in loco, bem como a coleta dos dados referentes ao tipo de solo, profundidade do lençol freático, dados geotécnicos, distância de corpos d'água e de conjuntos habitacionais. A coleta dos dados foi feita em documentos com a prefeitura e com outros órgãos municipais responsáveis (PMT, 2006).

Para realização do diagnóstico do aterro foi empregada a metodologia proposta pela CETESB (1998), que permite calcular o Índice de Qualidade de Aterros de Resíduos (IQR), mediante uso de um roteiro, na forma de checklist, que aborda 41 parâmetros de verificação pontuados de acordo com uma escala de valores envolvendo as características do local, a infraestrutura implantada e as condições operacionais. De acordo com a pontuação obtida (que varia de 0 a 10), a condição do local de disposição pode ser avaliada e classificada como adequada, controlada ou inadequada.

Dentre as limitações da metodologia empregada, pode-se citar o fato de que esta é uma ferramenta susceptível ao julgamento do técnico avaliador (CETESB, 2006). Além disso, de acordo com Cunha e Silva (2007), o atual índice não contempla os instrumentos de avaliação ambiental que incluem a questão dos mecanismos facilitadores para a viabilização do aproveitamento do biogás, bem como de mecanismos de gestão ambiental relacionados às normas de série ISO 14000.

Para obtenção do valor do IQR foi utilizada a equação 1:

$$
\mathrm{IQR}=(\mathrm{SUB} 1+\mathrm{SUB} 2+\mathrm{SUB} 3) 13
$$

Em que SUB1 é a somatória de questões referentes às características do local; SUB2 o conjunto de questões referentes à infraestrutura; e SUB3, às condições operacionais do aterro. Se o IQR for menor que 6 significa que as condições do aterro são inadequadas, se estiver entre 6 e 8 significa que as condições são controladas, e se estiver entre 8 e 10 significa que as condições do aterro são adequadas.

Após a avaliação e classificação do aterro, identificaram-se quais aspectos necessitavam ser melhorados visando a enquadrá-lo como aterro sanitário.

Para elaboração da proposta de melhoria do aterro adotou-se como referência os autores Barros, Tavares e Barros (2004), Bidone e Povinelli (1999), Castilhos Júnior (2003) e Jaramillo (1991), bem como o manual do IPT/CEMPRE (2000). 


\section{Progressão populacional e produção de lixo}

Para estimar o incremento populacional até o ano de 2015 (término da vida útil do aterro), foram empregadas as formulações de progressão geométrica (equações 2 e 3) apresentadas por Sperling (2005).

$$
\begin{gathered}
K_{g}=\frac{\ln P_{2}-\ln P_{0}}{t_{2}-t_{0}} \\
P_{t}=P_{0} \cdot e^{K g \cdot(t-t 0)}
\end{gathered}
$$

Em que:

$\mathrm{K}_{\mathrm{g}}=$ coeficiente

$\mathrm{P}_{0}=$ população urbana no ano de 1991 (população do antepenúltimo censo)

$\mathrm{P}_{2}=$ população urbana no ano de 2004 (população do último censo)

$\mathrm{t}_{0}=$ ano de 1991

$\mathrm{t}_{2}=$ ano de 2004

Os dados referentes ao número de habitantes que o município de Taquarituba possuía nos últimos censos demográficos do Instituto Brasileiro de Geografia e Estatística (IBGE, 2002) foram obtidos em documentos da prefeitura municipal.

Para avaliação da produção de lixo foram realizadas pesagens consecutivas dos caminhões de coleta de lixo para obtenção da média produzida diariamente, a qual foi dividida pela população atual, obtendo-se a quantidade média gerada por habitante. Este valor unitário foi multiplicado pelo número de habitantes de cada ano (até 2015) e assim se obteve a produção anual de lixo.

\section{Resultados e discussão}

\section{Avaliação do aterro do município de Taquarituba}

Os resultados da avaliação do aterro são apresentados na Tabela 1.

Tabela 1 - Resultados da avaliação do aterro e cálculo do IQR

\begin{tabular}{|c|c|c|c|c|c|c|c|c|}
\hline \multicolumn{9}{|c|}{ Características do local infraestrutura implantada condições operacionais } \\
\hline Subitem & Avaliação & Peso & Subitem & Avaliação & Peso & Subitem & Avaliação & Peso \\
\hline $\begin{array}{l}\text { Capacidade de } \\
\text { suporte do solo }\end{array}$ & Adequada & 5 & $\begin{array}{l}\text { Cercamento } \\
\text { da área }\end{array}$ & Não & 0 & Aspecto Geral & Ruim & 0 \\
\hline $\begin{array}{l}\text { Proximidade de } \\
\text { núcleos } \\
\text { Habitacionais }\end{array}$ & $\begin{array}{l}\text { Longe }> \\
500 \mathrm{~m}\end{array}$ & 5 & Portaria/Guarita & Não & 0 & $\begin{array}{l}\text { Ocorrência de } \\
\text { lixo descoberto }\end{array}$ & $\operatorname{Sim}$ & 0 \\
\hline $\begin{array}{l}\text { Proximidade de } \\
\text { corpos d'água }\end{array}$ & $\begin{array}{l}\text { Longe }> \\
200 \mathrm{~m}\end{array}$ & 3 & $\begin{array}{l}\text { Impermeabiliza- } \\
\text { ção de base } \\
\text { do aterro }\end{array}$ & Não & 0 & $\begin{array}{l}\text { Recobrimento } \\
\text { do lixo }\end{array}$ & Inadequado & 1 \\
\hline
\end{tabular}

(continua) 
Tabela 1 - Resultados da avaliação do aterro e cálculo do IQR

(continua)

\section{Características do local infraestrutura implantada condições operacionais}

\begin{tabular}{|c|c|c|c|c|c|c|c|c|}
\hline Subitem & Avaliação & Peso & Subitem & Avaliação & Peso & Subitem & Avaliação & Peso \\
\hline $\begin{array}{l}\text { Profundidade do } \\
\text { lençol freático }\end{array}$ & $>3 \mathrm{~m}$ & 4 & $\begin{array}{l}\text { Drenagem de } \\
\text { chorume }\end{array}$ & Inexistente & 0 & $\begin{array}{l}\text { Presença de urubus } \\
\text { ou gaivotas }\end{array}$ & Sim & 0 \\
\hline $\begin{array}{l}\text { Permeabilidade } \\
\text { do solo }\end{array}$ & Baixa & 5 & $\begin{array}{l}\text { Drenagem de } \\
\text { águas pluviais } \\
\text { (definitiva) }\end{array}$ & Inexistente & 0 & $\begin{array}{l}\text { Presença de } \\
\text { moscas em grande } \\
\text { quantidade }\end{array}$ & Sim & 0 \\
\hline $\begin{array}{l}\text { Disponibilidade } \\
\text { de material para } \\
\text { recobrimento }\end{array}$ & Suficiente & 4 & $\begin{array}{l}\text { Drenagem de } \\
\text { águas pluviais } \\
\text { (provisória) }\end{array}$ & Inexistente & 0 & $\begin{array}{l}\text { Presença de } \\
\text { catadores }\end{array}$ & Não & 3 \\
\hline $\begin{array}{l}\text { Qualidade do } \\
\text { material para } \\
\text { recobrimento }\end{array}$ & Boa & 2 & $\begin{array}{l}\text { Trator de esteira } \\
\text { ou compatível }\end{array}$ & Permanente & 5 & $\begin{array}{l}\text { Criação de animais } \\
\text { (porcos, bois, etc.) }\end{array}$ & Não & 4 \\
\hline $\begin{array}{l}\text { Condições do } \\
\text { sistema viário, } \\
\text { trânsito e acesso }\end{array}$ & Boas & 3 & $\begin{array}{l}\text { Outros } \\
\text { equipamentos, } \\
\text { trânsito e acesso }\end{array}$ & Sim & 1 & $\begin{array}{l}\text { Descarga de } \\
\text { resíduos de } \\
\text { serviços de saúde }\end{array}$ & Não & 3 \\
\hline $\begin{array}{l}\text { Isolamento visual } \\
\text { da vizinhança }\end{array}$ & Ruim & 0 & $\begin{array}{l}\text { Sistema de } \\
\text { tratamento de } \\
\text { chorume }\end{array}$ & $\begin{array}{l}\text { Insuf./ } \\
\text { Inexist. }\end{array}$ & 0 & $\begin{array}{l}\text { Descarga de } \\
\text { resíduos industriais }\end{array}$ & Não/Adeq. & 4 \\
\hline \multirow[t]{6}{*}{$\begin{array}{l}\text { Legalização da } \\
\text { localização }\end{array}$} & $\begin{array}{l}\text { Local } \\
\text { permitido }\end{array}$ & 5 & $\begin{array}{l}\text { Acesso à frente } \\
\text { de trabalho }\end{array}$ & Ruim & 0 & $\begin{array}{l}\text { Funcionamento } \\
\text { da drenagem } \\
\text { pluvial definitiva }\end{array}$ & Inexistente & 0 \\
\hline & & & Vigilantes & Não & 0 & $\begin{array}{l}\text { Funcionamento } \\
\text { da drenagem } \\
\text { pluvial provisória }\end{array}$ & Inexistente & 0 \\
\hline & & & $\begin{array}{l}\text { Sistema de } \\
\text { drenagem gases }\end{array}$ & Inexistente & 0 & $\begin{array}{l}\text { Funcionamento } \\
\text { da drenagem de } \\
\text { chorume }\end{array}$ & Inexistente & 0 \\
\hline & & & $\begin{array}{l}\text { Controle do } \\
\text { recebimento de } \\
\text { cargas }\end{array}$ & Não & 0 & $\begin{array}{l}\text { Funcionamento } \\
\text { do sistema de } \\
\text { tratamento de } \\
\text { chorume }\end{array}$ & Inexistente & 0 \\
\hline & & & $\begin{array}{l}\text { Monitorização } \\
\text { de águas } \\
\text { subterrâneas }\end{array}$ & Inexistente & 0 & $\begin{array}{l}\text { Funcionamento } \\
\text { do sistema de } \\
\text { monitorização } \\
\text { das águas } \\
\text { subterrâneas }\end{array}$ & Inexistente & 0 \\
\hline & & & $\begin{array}{l}\text { Atendimento a } \\
\text { estipulações de } \\
\text { projeto }\end{array}$ & Parcialmente & 1 & $\begin{array}{l}\text { Eficiência } \\
\text { da equipe de } \\
\text { vigilância }\end{array}$ & Ruim & 0 \\
\hline
\end{tabular}

Rev. Acad., Ciênc. Agrár. Ambient., Curitiba, v. 8, n. 2, p. 191-203, abr./jun. 2010 
Tabela 1 - Resultados da avaliação do aterro e cálculo do IQR

\begin{tabular}{ccc|cc|lcc}
\hline \multicolumn{7}{c}{ Características do local infraestrutura implantada condições operacionais } \\
\hline Subitem Avaliação & Peso & Subitem & Avaliação & Peso & Subitem & Avaliação & Peso \\
\hline & & & & $\begin{array}{c}\text { Manutenção dos } \\
\text { acessos internos }\end{array}$ & Regular & 1 \\
& & & SUB 2 & & SUB 3 \\
& SUB 1 & & 7 & & 15 \\
\hline
\end{tabular}

Com a obtenção dos subtotais 1,2 e 3, foi possível a resolução da equação 1. O valor determinado para o IQR do aterro de disposição de resíduos de Taquarituba foi de 4,46, o que indicou condições inadequadas.

Em relação às características do local, foram identificados problemas com o isolamento visual da vizinhança. Quanto à infraestrutura, observou-se a falta de cercamento da área com portaria e vigilantes para o controle do recebimento de cargas. Além disso, o local não possuía drenagem e tratamento de chorume, drenagem de gases, drenagem de águas pluviais, impermeabilização do terreno e monitoramento das águas subterrâneas.

Em relação às condições operacionais, o lixo não recebia recobrimento adequado, conforme preconizado pela NBR 8419 (ABNT, 1992), e ficava descoberto em média por uma semana, o que permitia a presença demasiada de insetos e demais vetores.

\section{Projeto de adequação do aterro}

Na Tabela 2 são apresentados os resultados da progressão populacional até o ano de 2015 e a respectiva produção de resíduos sólidos nesse período, levando em consideração que a população atual do município abrangida pela coleta é de 21.395 habitantes, e que são recolhidos em média $9.400 \mathrm{~kg} / \mathrm{dia}$. A cota per capita calculada foi de $0,44 \mathrm{~kg} / \mathrm{hab} . /$ dia.

Tabela 2 - Volume de resíduos a ser aterrado anualmente até 2015

(continua)

\begin{tabular}{lcccccc}
\hline Ano & $\begin{array}{c}\text { População } \\
\text { Urbana } \\
\text { (hab.) }\end{array}$ & $\begin{array}{c}\text { Cota } \\
\text { per capita } \\
(\mathbf{k g} / \text { hab./dia) }\end{array}$ & $\begin{array}{c}\text { Volume } \\
\text { de resíduo } \\
\left(\mathbf{m}^{3} / \mathbf{d i a}\right)\end{array}$ & $\begin{array}{c}\text { Material de } \\
\text { cobertura } \\
(\mathbf{\%})\end{array}$ & $\begin{array}{c}\text { Volume } \\
\text { aterrado/ } \\
\text { ano }\left(\mathbf{m}^{3}\right)\end{array}$ & $\begin{array}{c}\text { Somatória } \\
\text { ocupação } \\
\left(\mathbf{m}^{3}\right)\end{array}$ \\
\hline $\mathbf{2 0 0 6}$ & 21.395 & 0,44 & 13,45 & 20 & 5890,35 & 0 \\
$\mathbf{2 0 0 7}$ & 22.100 & 0,44 & 13,89 & 20 & 6084,44 & 6084,44 \\
$\mathbf{2 0 0 8}$ & 22.828 & 0,44 & 14,35 & 20 & 6284,87 & 12369,32 \\
$\mathbf{2 0 0 9}$ & 23.580 & 0,44 & 14,82 & 20 & 6491,91 & 18861,23 \\
$\mathbf{2 0 1 0}$ & 24.356 & 0,44 & 15,31 & 20 & 6705,55 & 25566,78 \\
$\mathbf{2 0 1 1}$ & 25.158 & 0,44 & 15,81 & 20 & 6926,35 & 32493,14 \\
$\mathbf{2 0 1 2}$ & 25.987 & 0,44 & 16,33 & 20 & 7154,59 & 39647,73
\end{tabular}

Rev. Acad., Ciênc. Agrár. Ambient., Curitiba, v. 8, n. 2, p. 191-203, abr./jun. 2010 
Tabela 2 - Volume de resíduos a ser aterrado anualmente até 2015

(conclusão)

\begin{tabular}{lcccccc}
\hline Ano & $\begin{array}{c}\text { População } \\
\text { Urbana } \\
\text { (hab.) }\end{array}$ & $\begin{array}{c}\text { Cota } \\
\text { per capita } \\
(\mathrm{kg} / \text { hab./dia) }\end{array}$ & $\begin{array}{c}\text { Volume } \\
\text { de resíduo } \\
\left(\mathrm{m}^{3} / \text { dia) }\right.\end{array}$ & $\begin{array}{c}\text { Material de } \\
\text { cobertura } \\
\mathbf{( \% )}\end{array}$ & $\begin{array}{c}\text { Volume } \\
\text { aterrado/ } \\
\text { ano }\left(\mathrm{m}^{3}\right)\end{array}$ & $\begin{array}{c}\text { Somatória } \\
\text { ocupação } \\
\left(\mathrm{m}^{3}\right)\end{array}$ \\
\hline $\mathbf{2 0 1 3}$ & 26.842 & 0,44 & 16,87 & 20 & 7389,98 & 47037,72 \\
$\mathbf{2 0 1 4}$ & 27.726 & 0,44 & 17,43 & 20 & 7633,36 & 54671,08 \\
$\mathbf{2 0 1 5}$ & 28.639 & 0,44 & 18 & 20 & 7884,72 & 62555,81 \\
\hline
\end{tabular}

\section{Método de operação e dimensionamento das trincheiras}

Pelo fato do terreno ser levemente inclinado e pela produção diária de lixo ser menor que 10 toneladas, adotou-se o método de grandes trincheiras (BIDONE; POVINELLI, 1999). Dessa forma, o caminhão de lixo pode ingressar no interior das trincheiras e depositar os resíduos contra as paredes da destas, ou da célula anterior, recebendo compactação e recobrimento diário com o próprio material de escavação.

As dimensões das trincheiras foram estabelecidas acompanhando as características do terreno. Foi adotado um formato trapezoidal de taludes 1:1, com Profundidade (P) de $4 \mathrm{~m}$, que é o máximo recomendado por Bidone e Povinelli (1999). A segurança em adotar profundidade de $4 \mathrm{~m}$ levou em consideração a profundidade do lençol freático em relação à superfície do terreno, que neste caso é de $8 \mathrm{~m}$.

Estabeleceu-se a Largura do Topo da Trincheira (LT) de 48 m, a Largura da Base (LB) de 40 m, e como o terreno possui irregularidades, os comprimentos (CT e CB) apresentaram-se variados. O esquema proposto para as trincheiras está representado na Figura 1.
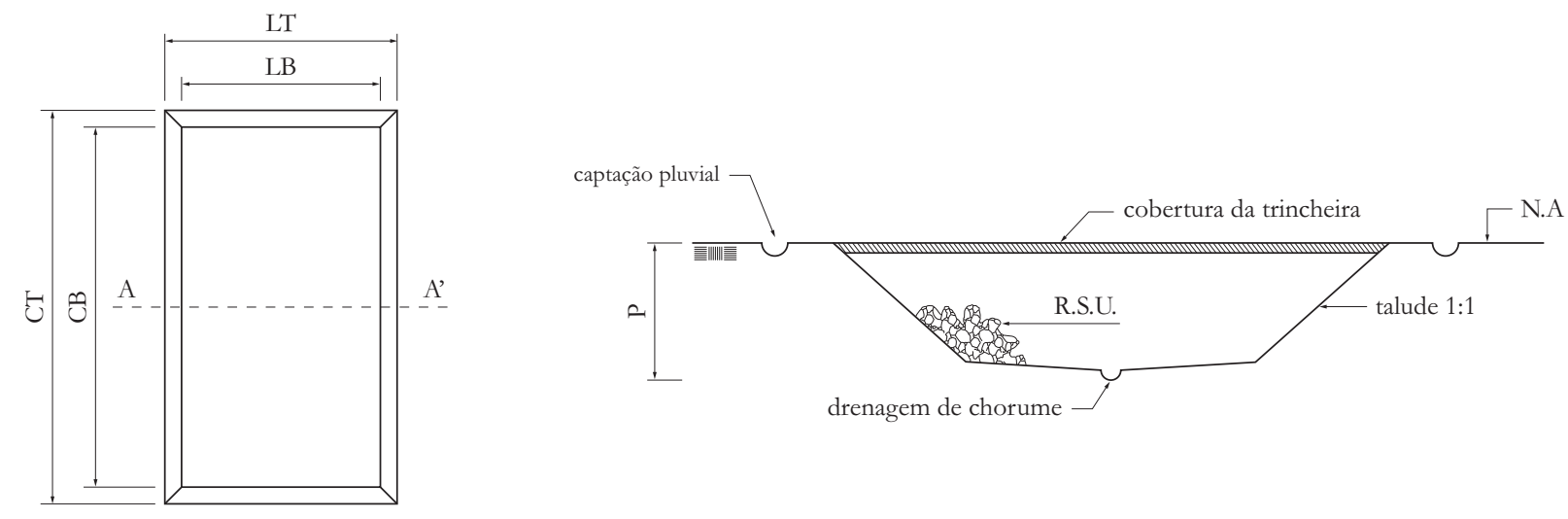

Figura 1 - Trincheira em planta em corte A-A'

A determinação da capacidade volumétrica da trincheira depende da densidade dos resíduos, que por sua vez varia de acordo com a técnica de compactação destes. Quando a compactação é realizada de forma manual, a densidade dos resíduos recém-compactados varia de 400 a $500 \mathrm{~kg} / \mathrm{m}^{3}$ (JARAMILLO, 
1991). Neste caso, foi adotada compactação mecanizada, portanto, a densidade considerada foi de $700 \mathrm{~kg} / \mathrm{m}^{3}$ (BIDONE; POVINELLI, 1999).

Além disso, é recomendado o recobrimento diário dos resíduos com $10 \mathrm{~cm}$ a $20 \mathrm{~cm}$ de solo local, o que corresponde a aproximadamente $20 \%$ do volume de resíduos aterrados (BIDONE; POVINELLI,1999). Com esses dados, foi calculado o volume da ocupação anual do aterro, bem como a somatória desta ocupação (Tabela 2).

A partir dos cálculos, oito trincheiras foram distribuídas no terreno, sendo que ao total as mesmas possuem capacidade para receber $61.852 \mathrm{~m}^{3}$ de resíduos. Com o início da operação ocorrido em janeiro de 2007, esta perpetuará praticamente até o final de 2015. Assim, a vida útil do aterro está prevista para aproximadamente 8,8 anos.

Vale ressaltar que as medidas propostas no presente trabalho tiveram o objetivo de projetar um aterro sanitário de forma que atendesse à legislação estadual e à realidade financeira municipal. Os resultados da avaliação do aterro permitiram a identificação dos pontos positivos e dos pontos a melhorar. Portanto, a ótima localização do terreno, o tipo de solo e a profundidade do lençol freático induziram a proposição de medidas para adequar o aterro existente, sem, no entanto, alterar sua localização.

\section{Sistema de impermeabilização}

A necessidade de impermeabilização do fundo e das laterais das trincheiras depende da profundidade do lençol freático e da condutividade hidráulica do solo, ou seja, da potencialidade de infiltração de líquidos no solo. Para Castilhos Junior (2003), solos com baixa condutividade hidráulica $\left(<10^{-4} \mathrm{~cm} / \mathrm{s}\right)$ apresentam maior potencial de serem utilizados como camadas de impermeabilização.

Foram realizados estudos geológico-geotécnicos, com sondagens à percussão no solo da área de influência do aterro (PMT, 2006), e os resultados constataram que a formação geológica local era de natureza predominantemente argilosa, Formação Teresina, do Grupo Passa Dois, Permiano Superior, constituindo solo/latossolo de cor marrom avermelhado intenso e de textura compacta. O estudo determinou a condutividade hidráulica entre $1,8 \times 10^{-6}$ a $2,4 \times 10^{-6} \mathrm{~cm} \cdot \mathrm{s}^{-1}$ e ausência de água até a profundidade de $8 \mathrm{~m}$ em relação à superfície do terreno.

Portanto, não foi proposto para as trincheiras impermeabilização de fundo e de laterais com membranas sintéticas ou outros materiais, pois as características geológicas do solo local atenderam ao requisito mínimo citado por Castilhos Junior (2003), em conformidade com os aspectos legais e normativos. É importante salientar a prévia compactação mecanizada da área de alocação das trincheiras.

\section{Sistema de cobertura dos RSU}

O sistema de cobertura dos resíduos tem as funções de eliminar a proliferação de vetores, diminuir a taxa de formação de lixiviados, reduzir a exalação de odores e impedir a saída descontrolada do biogás (CASTILHOS Jr., 2003). Pela razão da boa qualidade do solo local, o solo da própria escavação da trincheira deverá ser depositado e compactado mecanicamente ao fim de cada jornada de trabalho com uma cobertura de cerca de $10 \mathrm{~cm}$ a $20 \mathrm{~cm}$ de solo, e para o fechamento da trincheira, deverão ser empregados $60 \mathrm{~cm}$ de solo.

\section{Sistema de drenagem superficial}

O sistema de drenagem superficial tem a função de evitar a entrada descontrolada de água nas trincheiras, pois a água pluvial, além de aumentar o volume de lixiviados, gera erosão, que pode causar a destruição da camada de cobertura e dos taludes.

Rev. Acad., Ciênc. Agrár. Ambient., Curitiba, v. 8, n. 2, p. 191-203, abr./jun. 2010 
No dimensionamento dos canais, foram adotadas as recomendações propostas por Jaramillo (1991). $\mathrm{Na}$ Figura 2 está representado o desenho esquemático do sistema de drenagem de água pluvial, que apresenta formato trapezoidal, sem revestimento interno, e que tem por objetivo afastar a água de chuva das trincheiras. O NA representa o nível da água.

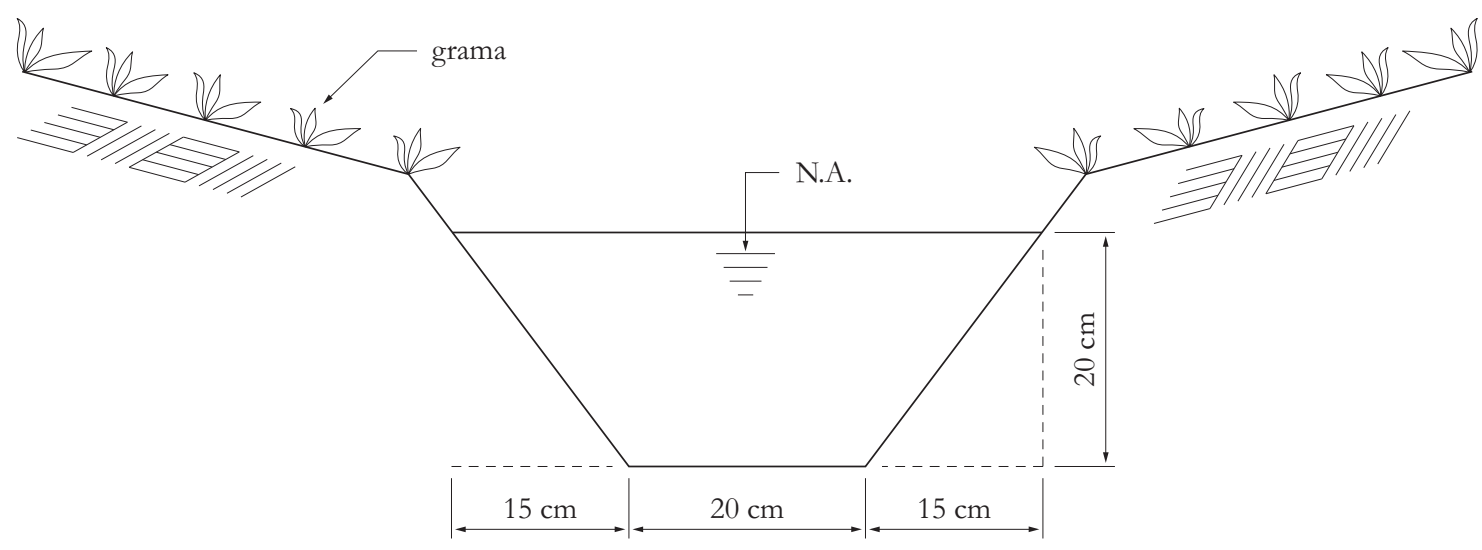

Figura 2 - Detalhe da seção transversal do canal trapezoidal

\section{Sistema de captação e tratamento de chorume}

Segundo Bidone e Povinelli (1999), o processo de decomposição da matéria orgânica que ocorre em aterros sanitários, predominantemente anaeróbio, gera como subproduto da atividade bacteriana o chorume, líquido negro, ácido, e malcheiroso. Como este resíduo possui elevada carga de demanda bioquímica de oxigênio (DBO), é necessário realizar sua coleta e tratamento para evitar a poluição.

Castilhos Junior (2003), Jaramillo (1991) e Monteiro et al. (2001) apresentam que o formato mais adequado para o sistema de drenagem de chorume é do tipo “espinha de peixe”. Seguindo outras recomendações dos mesmos autores, projetou-se a alocação de tubos de concreto no fundo das trincheiras, com formato "meia cana" de 0,2 m de diâmetro. Estes drenos deverão ser preenchidos com brita n. 3 e, para que não ocorra colmatação, deverão ser cobertos com capim seco.

Todo o lixiviado coletado será destinado para uma caixa de acumulação, ou seja, um poço construído em concreto, cujas dimensões são de 1,5 m de diâmetro e $6 \mathrm{~m}$ de profundidade. Quando a caixa de acumulação estiver com sua capacidade quase que totalizada, ela deverá ser esgotada com auxílio de um caminhão "limpa fossa" e, em seguida, deverá ser realizada a recirculação do lixiviado sobre a massa de lixo a ser aterrada.

A recirculação do chorume é um sistema de tratamento alternativo que, segundo Castilhos Junior (2003), possibilita a redução da carga orgânica e a aceleração da estabilização do aterro sanitário. Mas o autor ressalta que este método depende das características de cada projeto e não pode ser generalizado. Neste caso, a decisão em recircular o lixiviado levou em conta o pequeno volume a ser gerado, bem como as características de permeabilidade do solo e de profundidade do lençol freático, o que tecnicamente possibilitou a escolha desse método alternativo e aboliu a instalação de um sistema para tratamento dos lixiviados. Aliado a isso, o fator econômico e operacional das alternativas de tratamento propostas foram relevantes. 


\section{Sistema de captação de gases}

Os gases, principalmente metano e dióxido de carbono, são formados dentro das trincheiras pela degradação da matéria orgânica. Embora a geração desses gases seja relativamente baixa em pequenos sistemas de aterramento de resíduos, sua drenagem deve ser realizada. Esta medida se faz necessária para evitar bolsões de gás dentro das trincheiras, que podem causar incêndios locais, além de ocupar área dos resíduos.

Bidone e Povinelli (1999) propõem que a drenagem vertical dos gases seja realizada pela superposição de tubos de concreto, com diâmetro variando de $0,20 \mathrm{~m}$ a $1,00 \mathrm{~m}$, e revestidos com brita n. 2 .

A observação da grande quantidade de pneus descartados no aterro, que muitas vezes eram queimados no local, além do conhecimento a respeito dos escassos recursos financeiros da prefeitura do município, permitiu a proposição de uma solução alternativa que fosse técnica, econômica e ambientalmente adequada para o sistema de drenagem dos gases gerados e para o descarte inadequado de pneus no aterro.

A alternativa proposta utiliza pneus de caminhão perfurados e sobrepostos uns aos outros de forma a constituir uma rede vertical de drenagem de gases. Os pneus deverão ser preenchidos com brita n. 2 (Figura 3). A distância recomendada por Bidone e Povinelli (1999) entre um dreno e outro varia de $30 \mathrm{~m}$ a $50 \mathrm{~m}$; dessa forma, dimensionou-se um dreno para cada trincheira.

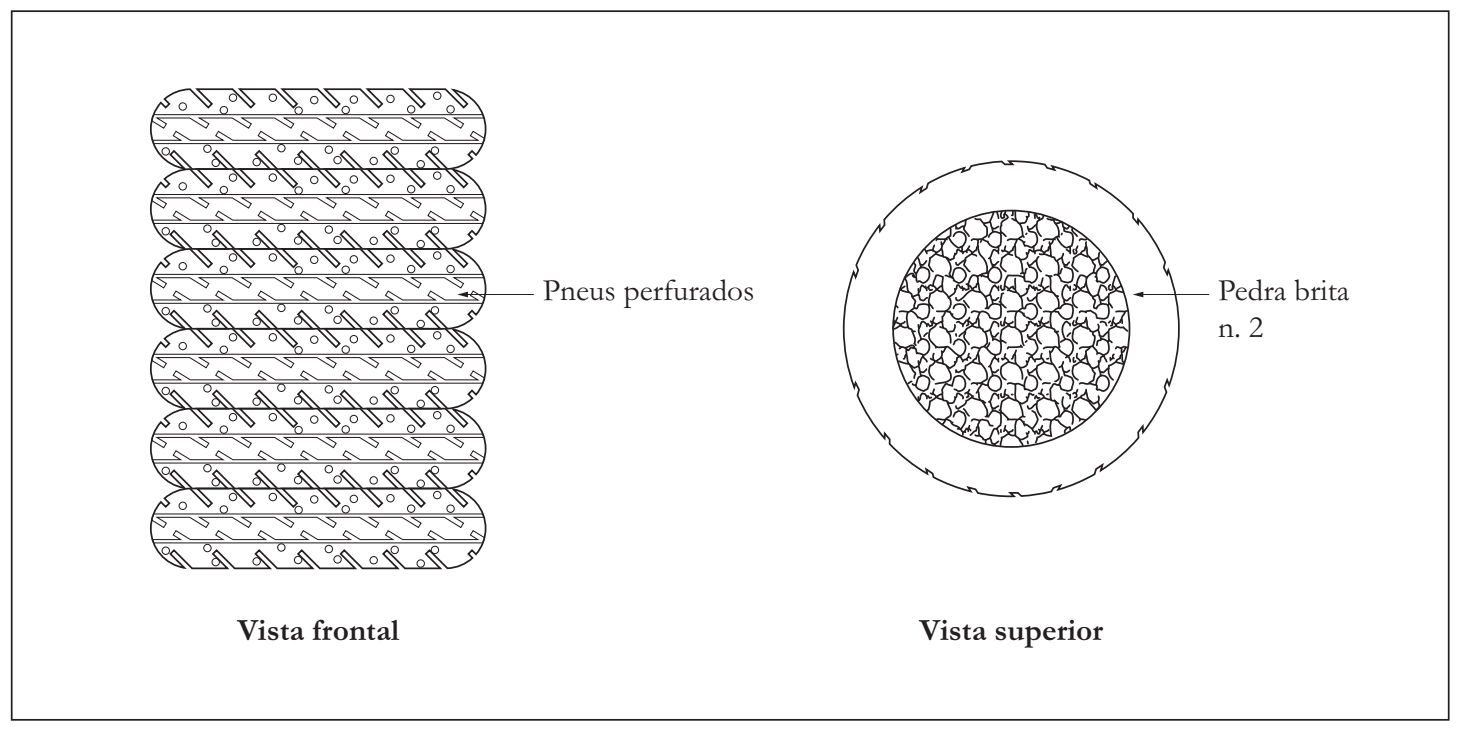

Figura 3 - Sistema de drenagem de gases

\section{Estruturas de controle}

Para que um aterro sanitário mantenha um bom padrão de funcionamento, é preciso haver estruturas de controle e proteção. Com o intuito de impedir a entrada de pessoas e animais na zona do aterro, como também evitar que papéis, plásticos e outros detritos sejam carregados pelo vento, recomendou-se a instalação de cercas de postes de concreto de 2,20 m de altura com 12 fios de arame farpado e um portão de entrada.

Projetou-se também uma portaria, com a guarita em uma parte e, ao lado, mas no mesmo prédio, a garagem para o maquinário e as ferramentas utilizadas na operação. Segundo Bidone e Povinelli (1999), esta estrutura é de suma importância, pois controla a entrada e saída de veículos na área do aterro, bem como o tipo de material que está sendo aterrado, evitando prejuízos ao andamento das obras.

Para melhor isolamento visual e de odores desagradáveis, recomendou-se barreira vegetal em paralelo com as cercas de postes. Mudas de árvores nativas da região deverão ser plantadas com espaçamento de $3 \mathrm{~m}$ entre si e intercaladas por arbustos.

Rev. Acad., Ciênc. Agrár. Ambient., Curitiba, v. 8, n. 2, p. 191-203, abr./jun. 2010 


\section{Implantação e operação}

A implantação e a operação do aterro de disposição final de resíduos sólidos urbanos do município de Taquarituba devem, até o fim de sua vida útil, seguir as seguintes recomendações:

- as trincheiras deverão ser abertas com retroescavadeira, com armazenamento do solo da escavação nas laterais delas;

- deverá ser utilizado rolo compactador corrugado (também conhecido como rolo pé de carneiro) ou trator de esteira (a depender da disponibilidade do município) para a compactação do fundo da trincheira, visando a diminuir a capacidade de infiltração do solo;

- deverá ser alocada toda a rede de drenagem de chorume e de águas pluviais, enquanto que a rede de drenagem de gases deverá ser montada em etapas, ou seja, no decorrer da ocupação da trincheira;

- os resíduos deverão ser descarregados com o ingresso dos veículos coletores no interior das trincheiras, sendo que, ao fim da jornada de trabalho de um dia, os resíduos devem ser compactados com trator de esteira ou rolo corrugado com três a cinco passadas (BIDONE; POVINELLI, 1999) e recobertos com $10 \mathrm{~cm}$ a $20 \mathrm{~cm}$ de solo local (retirado da própria escavação por ocasião da abertura das trincheiras). A camada de cobertura final da célula deve ter aproximadamente 60 cm de solo, sobre a qual se propõe a semeadura de gramíneas (CASTILHOS Jr., 2003).

Vale destacar que, no presente trabalho, não foi realizado estudo para a especificação do uso futuro da área após encerramento das atividades de disposição dos resíduos sólidos urbanos de Taquarituba. Entretanto, de acordo com o IPT/CEMPRE (2000), o uso futuro deverá preferencialmente se harmonizar com a ocupação nos entornos, sendo uma opção a utilização do local como área de recreação comunitária (parque ou campo para práticas esportivas). Tal utilização somente deverá ser implementada, no entanto, se os riscos de colapsos do solo, produção de biogás e demais fatores restritivos estiverem definitivamente reduzidos a níveis aceitáveis, definição essa que deverá ser avaliada cuidadosamente por ocasião da nova utilização da área.

$\mathrm{Na}$ Figura 4 é apresentada a área total do aterro, em planta, sendo que o polígono com hachura representa as células finalizadas pela operação anterior ao presente projeto, e em seu entorno estão localizadas as oito trincheiras com suas respectivas estruturas.

\section{Conclusões}

A metodologia de avaliação e classificação dos sistemas de disposição de RSU é uma importante ferramenta para identificação dos pontos que necessitam ser melhorados para enquadrar o aterro conforme as exigências ambientais. Portanto, este método pode ser adotado como um guia para elaboração do projeto almejado.

Com a proposta de adequação do aterro apresentado no presente trabalho, conclui-se que se as modificações estruturais e operacionais descritas no projeto forem realizadas, o novo valor de IQR poderá ser de 9,60, enquadrando o aterro de Taquarituba como aterro sanitário.

A vida útil prevista para o aterro antes da proposta de melhoria era de menos de quatro anos, graças à forma de operação que vinha sendo realizada. A nova proposta, se adotada, acarretará considerável aumento, previsto em 8,8 anos, em virtude do melhor aproveitamento da área.

A utilização de resíduos para construção de estruturas componentes do aterro, como proposto para o dreno de gases, bem como a possibilidade de não utilização de mantas plásticas na impermeabilização das laterais e do fundo do aterro, são fatores que reduzem os custos de implantação e que atendem à realidade financeira da prefeitura, porém, sem representar prejuízo aos compartimentos ambientais envolvidos e em conformidade com a legislação ambiental vigente, uma vez que toda a proposta foi baseada em procedimentos científicos constantes na literatura técnica da área.

Rev. Acad., Ciênc. Agrár. Ambient., Curitiba, v. 8, n. 2, p. 191-203, abr./jun. 2010 
Contudo, o principal benefício da proposta de melhoria do aterro de disposição de resíduos do município de Taquarituba será para a população, pois a confinação dos resíduos de forma segura previne a poluição ambiental. Além disso, evita-se o dispêndio de recursos públicos em multas e permite o contínuo funcionamento dos serviços, visto que a incorreta operação do aterro pode acarretar na interdição da área.

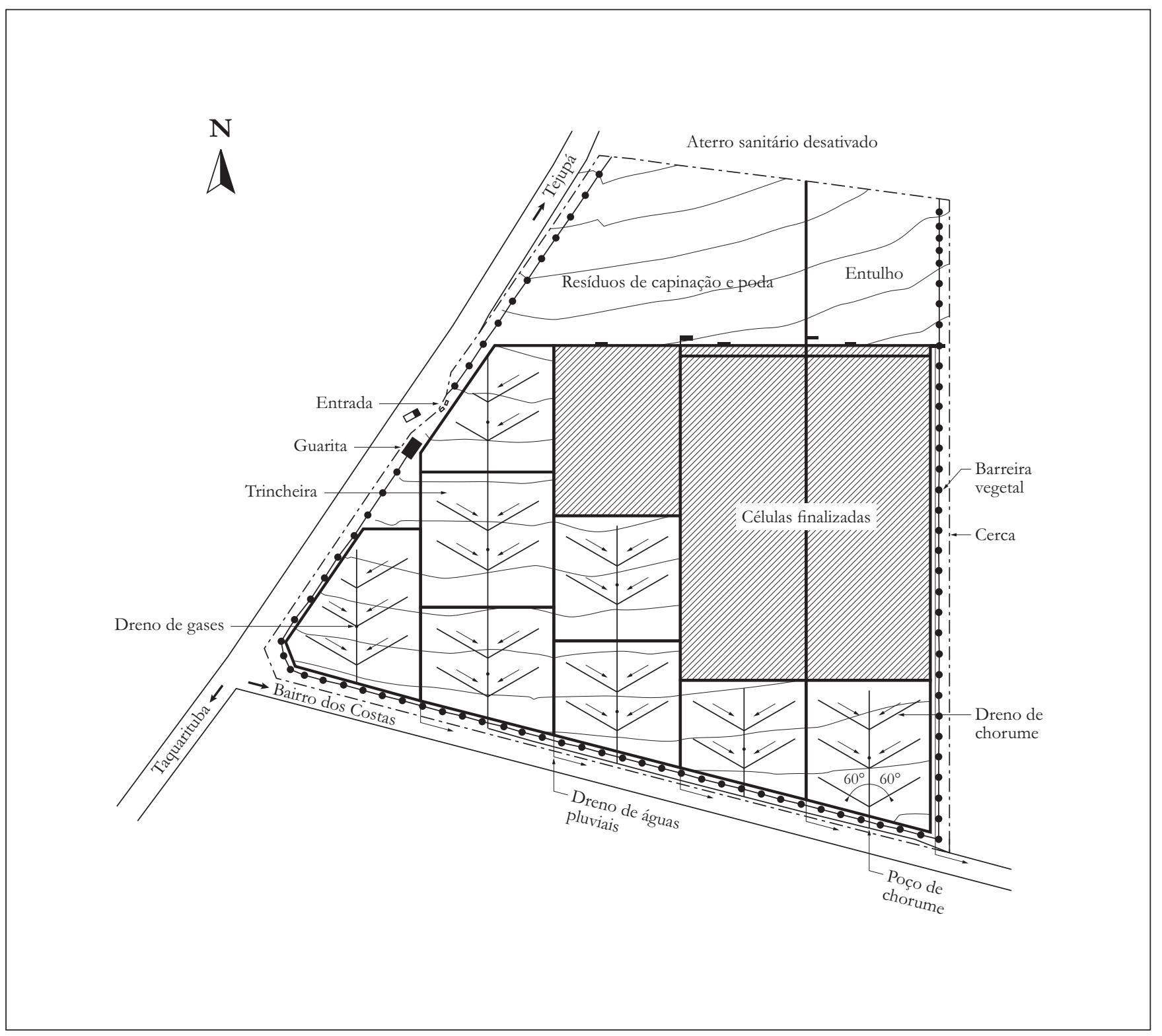

Figura 4 - Visualização esquemática do aterro com suas respectivas melhorias

\section{Referências}

ASSOCIAÇÃO BRASILEIRA DE NORMAS TÉCNICAS. NBR 8849: apresentação de projetos de aterros controlados de resíduos sólidos urbanos. Rio de Janeiro, 1985.

NBR 8419: apresentação de projetos de aterros sanitários de resíduos sólidos urbanos. Rio de Janeiro, 1992. 
BARROS, C.; TAVARES, C. R. G.; BARROS, S. T. D. Diagnóstico sobre a disposição final dos resíduos sólidos urbanos da cidade de Maringá, Estado do Paraná, Brasil. Acta Scientiarum Technology, v. 26, n. 2, p. 79-84, 2004.

BIDONE, F. R. A.; POVINELLI, J. Conceitos básicos de resíduos sólidos. São Carlos: EESC/USP, 1999.

CASTILHOS Jr., A. B. Resíduos sólidos urbanos: aterro sustentável para municípios de pequeno porte. Rio de Janeiro: Rima ABES, 2003.

COMPANHIA DE TECNOLOGIA ESANEAMENTO AMBIENTALDO ESTADO DESÃO PAULO_CETESB. Relatório Ambiental Preliminar (RAP), Roteiros básicos. São Paulo: CETESB, 1998. 80 p. Documentos ambientais. COMPANHIA DE TECNOLOGIA ESANEAMENTO AMBIENTALDO ESTADO DE SÃO PAULO_CETESB. Inventário estadual de resíduos sólidos domiciliares: relatório de 2005. Disponível em: <http://www.cetesb. sp.gov.br>. Acesso em: 20 set. 2006.

CUNHA, M. E. G.; SILVA, M. F. Análise de instrumentos de gestão ambiental visando a melhoria contínua do Índice de Qualidade de Aterro de Resíduos - IQR do Estado de São Paulo. Revista Brasileira de Ciências Ambientais, n. 6, p. 9-13, 2007.

INSTITUTO BRASILEIRO DE GEOGRAFIA E ESTATÍSTICA - IBGE. Pesquisa Nacional de Saneamento Básico 2000. Rio de Janeiro: IBGE, 2002.

INSTITUTO DE PESQUISAS TECNOLÓGICAS - ITP/CEMPRE. Lixo municipal: manual de gerenciamento integrado. São Paulo: IPT/CEMPRE, 2000. 370 p.

JARAMILLO, J. Resíduos sólidos municipales: guia para el diseño, construccion y operacion de rellenos sanitários manuales. Washington: Pan American Health Organization, 1991. 214 p. (Série Técnica, 28).

MONTEIRO, J. H. P. et al. Manual de gerenciamento integrado de resíduos sólidos. Rio de Janeiro: IBAM, 2001. PREFEITURA MUNICIPAL DE TAQUARITUBA. Estudo técnico encomendado pela Prefeitura Municipal de Taquarituba, SP, para o projeto do aterro sanitário municipal. Taquarituba, SP: Arquivo da PMT, 2006.

SPERLING, M. V. Introdução à qualidade das águas e ao tratamento de esgotos. Belo Horizonte: Ed. da UFMG, 2005.

Recebido: 28/04/2009

Received: 04/28/2009

Aprovado: $26 / 03 / 2010$

Approved: 03/26/2010 